\title{
Pengetahuan Panen dan Produktivitas Tenaga Kerja Pemanenan Kelapa Sawit (Elaesis Guineensis Jacq) di PT Sentosa Kalimantan Jaya
}

\author{
Isti Isma \\ Pengelolaan Perkebunan, Politeknik \\ Pertanian Negeri Samarinda, \\ samarinda, 75131, \\ istiisma98@gmail.com
}

\author{
Budi Winarni \\ Pengelolaan Perkebunan, Politeknik \\ Pertanian Negeri Samarinda, \\ samarinda, 75131, \\ bwinarni14@gmail.com
}

\author{
Taman Alex* \\ Pengelolaan Perkebunan, Politeknik \\ Pertanian Negeri Samarinda, \\ samarinda, 75131 \\ tamanalex2@gmail.com \\ *Corresponding author
}

\begin{abstract}
Abstrak - Penelitian ini dilatarbelakangi oleh keberhasilan panen yang didukung oleh pengetahuan pemanenan sangat diperlukan untuk dapat menyelesaikan tugas-tugas pekerjaan agar hasil kerja menjadi maksimal. Tujuan dilakukannya penelitian ini adalah untuk mengetahui katagori pengetahuan pemanenan dan menghitung seberapa besar produktivitas tenaga kerja kerja pemanen kelapa sawit di PT Sentosa Kalimantan Jaya (SKJ). Metode penelitian yang digunakan adalah metode survai. Teknik pengolahan data penelitian menggunakan metode analisis deskriptif dengan membuat katagorisasi (lima katagori) untuk mengetahui pengetahuan tenaga kerja pemanenan melalui program Microsoft Exel. Dari hasil tabulasi pengetahuan tenaga kerja pemanenan termasuk dalam katagori baik dengan nilai 380. Jadi dapat disimpulkan bahwa pengetahuan tenaga kerja pemanenan di PT Sentosa Kalimantan Jaya (SKJ) termasuk dalam pengetahuan yang baik dan hasil rata-rata produktivitas adalah 222 janjang/HK dengan basis 181 janjang/HK.
\end{abstract}

Kata Kunci- Pengetahuan Panen, Produktivitas dan Tenaga Kerja

\section{PENDAHUluaN}

Kelapa sawit merupakan komoditas perkebunan unggulan di Indonesia. Tanaman yang produk utamanya terdiri dari minyak sawit (Crude Palm Oil) dan minyak inti sawit (Palm Kernel Oil) ini memiliki salah satu penyumbang devisa negara terbesar dibandingkan dengan komoditas perkebunan lain. Hingga saat ini kelapa sawit diusahakan dalam bentuk perkebunan dan pabrik pengelolahan kelapa sawit dari olahan mentah hingga menjadi olahan jadi atau siap pakai. Dengan demikian, kelapa sawit memiliki arti yang sangat penting bagi perekonomian di Indonesia (Fauzi, 2012).

Tenaga kerja merupakan faktor yang penting karena tenaga kerja ialah pelaku ekonomi atau orang yang bekerja, sedangkan faktor produksi lainnya bersifat pasif seperti, modal, bahan baku, mesin dan tanah. Tenaga kerja dapat mempengaruhi dan melakukan manajemen terhadap faktor produksi lainnya yang terlibat dalam proses produksi (Sumarsono, 2009).

Menurut Lubis (1992), menyatakan bahwa keberhasilan pemanenan dan produksi kelapa sawit sangat bergantung pada bahan tanam, pemanen, alat panen, kelancaran transportasi, organisasi pemanen, keadaan areal dan intensif yang diberikan. Mangoensoekarjo dan Semangun (2008) mengatakan bahwa panen yaitu pemotongan tandan buah matang, pengutipan brondolan, pemotongan pelepah, pengangkutan hasil ke Tempat Penimpanan Hasil (TPH) dan pengangkutan hasil ke pabrik. Untuk menghasilkan panen yang baik diperlukan adanya pengetahuan panen yaitu persiapan panen, kriteria matang panen, rotasi panen, sistem panen dan sarana pasca panen. Hal ini merupakan faktor yang saling berhubungan satu dengan lainnya.

\section{METODE PENELITIAN}

A. Lokasi dan Waktu Penelitian

Penelitian ini dilaksanakan di perusahaan PT Sentosa Kalimantan Jaya, waktu penelitian dilaksanakan mulai dari 1 Oktober sampai dengan 13 November 2020.

\section{B. Alat dan Bahan Penelitian}

Alat dan bahan ynag digunakan dalam penelitian ini yaitu:

1. Alat
a. Laptop
b. Alat Tulis
c. Kamera/handpone
d. Program Microsoft Office Word
e. Program Microsoft Office Exel

2. Bahan
a. Lembar Observasi
b. Lembar Wawancara
c. Lembar Kuesioner
d. Dokumentasi
C. Metode Pengambilan Data

Data yang diambil penelitian ini terdiri dari data primer dan data sekunder.

1. Data Primer 
a. Observasi

Observasi dilakukan untuk menggumpul data dengan meninjau atau menggunjungi perusahaan secara langsung dengan mencatat informasi yang berhubungan dengan masalah yang diteliti.

b. Wawancara

Wawancara dilakukan dengan cara tanya jawab secara langsung kepada karyawan panen untuk mengumpulkan dan menggali informasi ynag dibutuhkan dalam penelitian.

c. Kuesioner

Kuesioner merupakan teknik pengambilan data dengan memberikaan pertanyaan atau pernyataan secara tertulis kepada responden untuk dijawabnya (Sugiyono,2013).

d. Dokumentasi

Pengambilan gambar pada saat dilakukannya wawancara dan pengisian kuesioner guna menunjang dalam penelitian.

2. Data Sekunder
a. Dokumentasi perusahaan
Mengumpulkan dokumen dan arsip perusahaan yang berkaitan dengan pemanenan dan data lain untuk mendukung penelitian yang ada di perusahaan tempat penelitian.
b. Studi pustaka
Mengumpulkan informasi yang bersumber informasi pendukung penelitian di lapangan. dari buku, internet dan dokumen lain sebagai

3. Sampel

Sampel adalah bagian dari populasi yang diambil melalui cara-cara tertentu yang memiliki karateristik dengan jelas dan lengkap yang dianggap bisa mewakili populasi (Iqbal, 2002).

Untuk menentukan jumlah sampel responden digunakan pengambilan sensus. Jika populasinya kurang dari 100 orang, maka jumlah sampelnya diambil $10-15 \%$ atau $20-25 \%$ dari jumlah populasi (Arikunto, 2013). Dalam penelitian ini dilakukan pengambilan responden secara keseluruhan sebanyak 21 responden dalam satu afeling di PT Sentosa Kalimantan Jaya.

\section{Metode Penelitian}

Metode yang digunakan dalam penelitian ini adalah metode survai, karena penelitian ini menggunakan sampel dari satu populasi di afdeling 1 dan menggunakan lembar kuesioner sebagai alat pengumpulan data pokok (Singarimbun dan Effendi, 2011).

\section{E. Prosedur Kerja}

Prosedur kerja Tingkat Pengetahuan Tenaga Kerja Pemanenan Kelapa Sawit yaitu sebagai berikut:
1. Tahap persiapan untuk penelitian skripsi dengan mendatangi objek.

2. Peninjauan di lapangan secara langsung, untuk mengetahui jumlah karyawan yang ada sebagai sampel pengambilan data dalam penelitian. Jumlah responden yang diambil sebanyak 21 orang di afdeling 1.

3. Menentukan jumlah tim kerja dan lokasi kerjanya yang akan menjadi objek penelitian

4. Melakukan pengamatan secara langsung dilapangan terhadap proses pegambilan data tinggat pengetahuan tenaga kerja pemanenan kepala sawit.

5. Pengambilan data yang dilakukan dalam penelitian yaitu menggunakan data primer dan sekunder berupa: observasi, wawancara, kuesioner dan lembaga-lembaga yang bersangkutan.

6. Melakukan dokumentasi berupa gambar yang berkaitan dengan pengambilan data sebagai bukti dalam penelitian dilapangan.

Pengelolaan data antara lain, memeriksa data yang telah didapatkan dari lapangan kemudian diolah.

\section{F. Metode Analisis Data}

Dalam membahas hasil penelitian penulis menggunakan metode analisis deskriptif, yaitu suatu cara penulisan yang mengumpulkan, mengklasifikasikan datadata serta selanjutnya menganalisa data sedemikian rupa dihubungkan dengan teori-teori yang berkaitan dengan masalah yang dibahas untuk mengambil kesimpulan.

Bobot atau nilai dari masing-masing jawaban yang dipilih oleh responden menurut Skala Likert adalah sebagai berikut :

1. Jika jawaban yang dipilih adalah Sangat Baik (SB) maka mempunyai bobot nilai 5

2. Jika jawaban yang dipilih adalah Baik (B) maka mempunyai bobot nilai 4

3. Jika jawaban yang dipilih adalah Cukup Baik (CB) maka mempunyai bobot nilai 3

4. Jika jawaban yang dipilih adalah Tidak Baik (CB) maka mempunyai bobot nilai 2

5. Jika jawaban yang dipilih adalah Sangat Tidak Baik (STB) maka mempunyai bobot nilai 1

Pada penelitian ini analisis deskriptif dilakukan dengan membuat kategorisasi (lima kategori) untuk mengetahui tingkat pengetahuan tenaga kerja pemanen di PT Sentosa Kalimantan Jaya Garis kategorisasi dibuat berdasarkan item pernyataan untuk menilai variabel dan juga jumlah sampel yang digunakan. Menurut Sugiyono (2013) rentang skor setiap kategori ditentukan sebagai:

Rentang skor kategori $=\frac{(\mathrm{JRx} J \mathrm{BxST})-(\mathrm{JR} \times \mathrm{BxSR})}{\mathrm{ST}}$

$\begin{array}{llll}\text { Keterangan : } & \text { JR } & \text { : } & \text { Jumlah responden } \\ & \text { JB } & : & \text { Jumlah butir soal } \\ & \text { ST } & : & \text { Skor tertinggi } \\ & \text { SR } & : & \text { Skor terendah }\end{array}$

Setelah diketahui rentang skor kategori setiap variabel, maka garis kategorisasi menurut Sugiyono (2013) 
digambarkan sebagaimana dapat dilihat pada gambar 1 berikut:

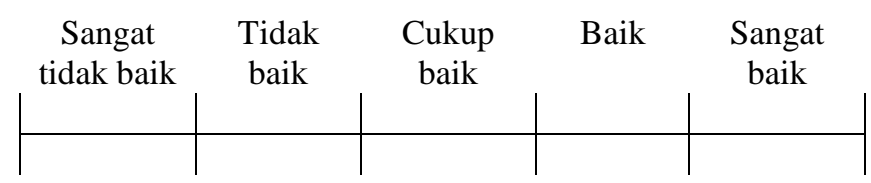

Gambar 1. Garis Kategorisasi Variabel

1. Penilaian Indikator Pengetahuan Pemanenan

Pengetahuan diukur berdasarkan pertanyaan terhadap indikator pengetahuan pemanen tentang persiapan alat panen, pemahaman kriteria matang panen buah kelapa sawit, pemahaman rotasi panen yang tepat, pemahaman sistem panen yang digunakan, dan sarana pasca panen yang digunakan.

1. Pengetahuan pemanen tentang persiapan alat panen, yaitu pengetahuan tenaga kerja pemanen tentang alat panen yang digunakan, seperti gancu, dodos, egrek, pikulan buah/ angkong, karung, ember ukuran $8 \mathrm{~kg}$, kapak, dan keranjang brondolan. Kategori untuk penilaian indikator ini adalah:

1 = Sangat Tidak Baik (tidak tahu sama sekali alat panen)

2 = Tidak Baik (tahu 1-2 alat panen)

3 = Cukup Baik (tahu 3-4 alat panen)

4 = Baik (tahu 5-6 alat panen)

$5=$ Sangat Baik (tahu $\geq 7$ alat panen).

2. Pemahaman kriteria matang panen buah kelapa sawit, yaitu pemahaman tenaga kerja pemanen pada tujuh kriteria matang panen, yaitu fraksi 00 (sangat mentah), fraksi 0 (mentah), fraksi 1 (kurang matang), fraksi 2 (matang I), fraksi 3 (matang II), fraksi 4 (lewat matang I), dan fraksi 5 (lewat matang II). Kategori untuk penilaian indikator ini adalah:

1 = Sangat Tidak Baik (tidak tahu sama sekali kriteria matang panen)

2 = Tidak Baik (tahu 1-2 kriteria matang panen)

3 = Cukup Baik (tahu 3-4 kriteria matang panen)

4 = Baik (tahu 5-6 kriteria matang panen)

5 = Sangat Baik (tahu semua kriteria matang panen).

3. Pemahaman rotasi panen yang tepat, yaitu pemahaman tenaga kerja pemanen pada giliran panen kelapa sawit, seperti 4/7, 5/7, 6/7 dan 7/7. Kategori untuk penilaian indikator ini yaitu:

1 = Sangat Tidak Baik (tidak mengerti sama sekali sistem rotasi panen kelapa sawit)

2 = Tidak Baik (mengerti 1 sistem rotasi panen)
3 = Cukup Baik (mengerti 2 sistem rotasi panen kelapa sawit)

4 = Baik (mengerti 3 sistem rotasi panen kelapa sawit)

5 = Sangat Baik (mengerti 4 sistem rotasi panen kelapa sawit).

4. Pemahaman sistem panen yang digunakan, yaitu pemahaman tenaga kerja pemanen pada sistem hanca giring, hanca tetap, dan hanca giring tetap. Kategori untuk penilaian indikator ini yaitu:

1 = Sangat Tidak Baik (tidak mengerti sama sekali sistem panen)

2 = Tidak Baik (mengerti 1 sistem panen)

3 = Cukup Baik (mengerti 2 sistem panen)

4 = Baik (mengerti 3 sistem panen)

5 = Sangat Baik (mengerti $>3$ sistem panen).

5. Sarana pasca panen yang digunakan, yaitu pemahaman tenaga kerja pemanen pada sarana yang diperlukan setelah melakukan panen, seperti identitas pemanen (nomor pemanen), transportasi pengangkutan buah, pengawasan muat angkut dan pengawasan mutu panen. Kategori untuk penilaian indikator ini yaitu:

1= Sangat Tidak Baik (tidak mengerti sama sekali sarana pasca panen)

2 = Tidak Baik (mengerti 1 sarana pasca panen)

$3=$ Cukup Baik (mengerti 2 sarana pasca panen)

4 = Baik (mengerti 3 sarana pasca panen)

$5=$ Sangat Baik (mengerti $>3$ sarana pasca panen).

2. Produktivitas tenaga kerja

Dalam penelitian ini produktivitas kerja dihitung dengan membagi hasil prosduksi dengan jumlah jamkerja. Menurut Hasibun (2009), menggunakan cara pengukuran produktivitas tenaga kerja yaitu sebagai berikut:

Produktivitas Tenaga Kerja $=\frac{\mathrm{O}}{\mathrm{NX} \mathrm{H}}$

Keterangan:

$\mathrm{O}=$ Output atau hasil

$\mathrm{N}=\mathrm{Jam} /$ hari kerja nyata

$\mathrm{H}=$ Jumlah tenaga kerja

\section{HASIL DAN PEMBAHASAN}

1. Kerakteristik Responden

\section{A. Hasil}

Penelitian ini menggunakan 21 responden dalam 1 afdeling. Karakteristik responden yang berkait dengan produktivitas tenaga kerja meliputi umur, masa kerja dan tingkat pendidikan. 
a. Karakteristik berdasarkan tingkat umur responden

Adapun karakteristik berdasarkan tingkat umur responden dapat dilihat pada tabel 2 berikut:

Tabel 2. Karakteristik berdasarkan tingkat umur responden.

\begin{tabular}{|c|c|c|}
\hline $\begin{array}{l}\text { Umur tenaga } \\
\text { kerja (Tahun) }\end{array}$ & Frekuensi (Orang) & Persentase \% \\
\hline $22-28$ & 4 & 19,05 \\
\hline $29-35$ & 5 & 23,81 \\
\hline $36-42$ & 8 & 38,09 \\
\hline $43-49$ & 4 & 19,05 \\
\hline Jumlah & 21 & 100 \\
\hline
\end{tabular}

b. Karakteristik berdasarkan masa kerja

Adapun karateristik berdasarkan masa kerja responden dapat dilihat pada tabel 3 berikut:

Tabel 3. Karakteristik berdasarkan masa kerja

\begin{tabular}{|c|c|c|}
\hline $\begin{array}{l}\text { Lama kerja } \\
\text { (Bulan) }\end{array}$ & $\begin{array}{l}\text { Frekuensi } \\
\text { (orang) }\end{array}$ & Persentasi \% \\
\hline $1-20$ & 14 & 66,67 \\
\hline $21-40$ & 5 & 23,81 \\
\hline $41-60$ & 0 & 0 \\
\hline $61-80$ & 2 & 9,52 \\
\hline Jumlah & 21 & 100 \\
\hline
\end{tabular}

c. Karakteristik berdasarkan tingkat pendidikan Adapun karakterik berdasarkan tingkat pendidikan dapat dilihat pada tabel 4 berikut:

Tabel 4. Karakteristik berdasarkan tingkat pendidikan

\begin{tabular}{|c|c|c|}
\hline $\begin{array}{l}\text { Tingkat } \\
\text { pendidikan }\end{array}$ & $\begin{array}{l}\text { Frekuensi } \\
\text { (Orang) }\end{array}$ & Persentasi \% \\
\hline $\begin{array}{c}\text { Tidak } \\
\text { sekolah }\end{array}$ & 2 & 9,52 \\
\hline SD & 14 & 66,67 \\
\hline SMP & 3 & 14,29 \\
\hline SMA/SMK & 2 & 9,52 \\
\hline Jumlah & 21 & 100 \\
\hline
\end{tabular}

2. Pengetahuan Responden

Tabel 5. Tabulasi Jawaban Pengetahuan Pemanen

\begin{tabular}{|c|c|c|c|c|c|}
\hline \multirow[b]{2}{*}{$\begin{array}{r}\text { Pernyataan } \\
\text { (Indikator) }\end{array}$} & \multicolumn{5}{|c|}{ Alternatif Jawaban (Nilai Katagori) } \\
\hline & $\begin{array}{l}\text { SB } \\
(5)\end{array}$ & $\begin{array}{l}\text { B } \\
(4)\end{array}$ & $\begin{array}{l}\text { CB } \\
(3)\end{array}$ & $\begin{array}{l}\text { TB } \\
(2)\end{array}$ & $\begin{array}{l}\text { STB } \\
(1)\end{array}$ \\
\hline $\begin{array}{l}\text { Pengetahuan alat } \\
\text { panen }\end{array}$ & 21 & 0 & 0 & 0 & 0 \\
\hline $\begin{array}{l}\text { Kriteria matang } \\
\text { panen }\end{array}$ & 0 & 0 & 21 & 0 & 0 \\
\hline Rotasi panen & 0 & 0 & 15 & 4 & 2 \\
\hline $\begin{array}{l}\text { System panen } \\
\text { kelapa sawit }\end{array}$ & 0 & 1 & 17 & 1 & 2 \\
\hline $\begin{array}{ll}\text { Sarana } \\
\text { panen }\end{array}$ & 16 & 3 & 2 & 0 & 0 \\
\hline $\begin{array}{l}\text { Jumlah } \\
\text { (Frekuensi) }\end{array}$ & 37 & 4 & 55 & 5 & 4 \\
\hline Persentase & 35,238 & 3,810 & 52,381 & 4,762 & 3,810 \\
\hline
\end{tabular}

Keterangan:

STB (1) = Sangat Tidak Baik

TB (2) = Tidak Baik

CB (3) = Cukup Baik

$\mathrm{B}(4)=$ Baik

SB (5) = Sangat Baik

Tabel 6. Tabulasi Skor Jawaban Responden

\begin{tabular}{|l|l|l|l|l|}
\hline Tanggapan & $\begin{array}{l}\text { Nilai } \\
\text { katagor } \\
\text { i }\end{array}$ & $\begin{array}{l}\text { Frekuens } \\
\text { i }\end{array}$ & $\begin{array}{l}\text { Skor } \\
\%\end{array}$ & $\begin{array}{l}\text { (Frekuens } \\
\text { i x Nilai } \\
\text { Katagori) }\end{array}$ \\
\hline Sangat Baik & 5 & 37 & 35,238 & 185 \\
\hline Baik & 4 & 4 & 3,810 & 16 \\
\hline Cukup Baik & 3 & 55 & 52,381 & 165 \\
\hline Tidak Baik & 2 & 5 & 4,762 & 10 \\
\hline $\begin{array}{l}\text { Sangat } \\
\text { Tidak Baik }\end{array}$ & 1 & 4 & 3,810 & 4 \\
\hline \multicolumn{1}{|r|}{ Jumlah } & & 105 & 100 & 380 \\
\hline
\end{tabular}

Hasil perhitungan rentang skor yaitu sebagai berikut:

Skor ideal = Jumlah Frekuensi x Nilai Katagori

Skor tertinggi $=105 \times 5=525$

Skor terendah $=105 \times 1=105$

Rentang skor $=\frac{(525-105)}{5}=84$

Berdasarkan jumlah skor sebesar 380 maka dapat digambarkan tanggapan responden adalah baik seperti gambar berikut ini:

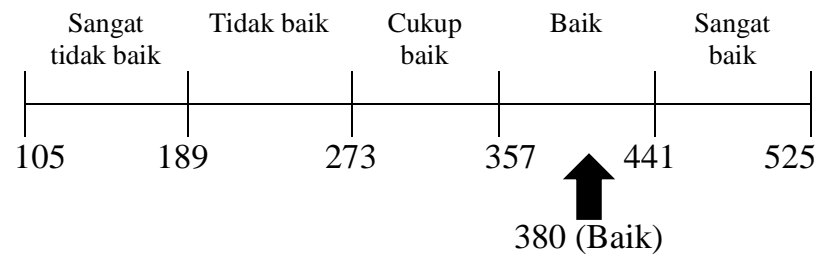

Keterangan:

Hasil perhitungan gambar di atas yaitu sebagai berikut:

Jumlah Frekuensi + Rentang Skor

Sangat Tidak Baik $=105+84=189$ dengan skor 105189

Tidak Baik $=189+84=273$ dengan skor 189-273

Cukup Baik $=273+84=357$ dengan skor 273-357

Baik $\quad=357+84=441$ dengan skor 357-441

Sangat Baik $=441+84=525$ dengan skor $441-525$

3. Produktivitas

Dapat dilihat tabel di bawah ini yaitu tabel produktivitas tenaga kerja pemanen kelapa sawit yang telah dijumlahkan lalu dirata-ratakan menjadi rata-rata produktivitas janjang/HK.

Tabel 7. Hasil rata-rata produktivitas tenaga kerja pemanenan kelapa sawit

\begin{tabular}{|l|l|c|}
\hline No. & Nama & $\begin{array}{l}\text { Rata-rata } \\
\text { Janjang/HK }\end{array}$ \\
\hline 1. & Ruslan & 293 \\
\hline 2. & Firman & 230 \\
\hline 3. & Jumadi & 256 \\
\hline 4. & Robert & 211 \\
\hline
\end{tabular}




\begin{tabular}{|l|l|l|}
\hline 5. & Sivilianus Mangge & 248 \\
\hline 6. & Mirwan & 262 \\
\hline 7. & Wahyudi & 210 \\
\hline 8. & Mansur & 235 \\
\hline 9. & Syamsudin & 208 \\
\hline 10. & Sudarman & 237 \\
\hline 11. & Andi Rendi & 188 \\
\hline 12. & Thomas & 186 \\
\hline 13. & Yosep & 184 \\
\hline 14. & Sirajudin & 212 \\
\hline 15. & Dominikus & 19 \\
\hline 16. & Nurdin & 60 \\
\hline 17. & Nomris & 192 \\
\hline 18. & Rahman & 234 \\
\hline 19. & Womito Hamsari & 191 \\
\hline 20. & Yunli Loinenak & 224 \\
\hline 21. & Laha & 207 \\
\hline Rata-rata Produktivitas Janjang/HK & 222 \\
\hline
\end{tabular}

\section{B. Pembahasan}

1. Karakteristik responden

a. Karakteristik berdasarkan tingkat umur responden

Dari hasil penelitian pada Tabel 2 umur terjaga kerja pemanen palinguda berumur 22-28 tahun dan paling tua berumur 43-49 tahun, umur tersebut masuk dalam kisaran umur tenaga kerja. Menurut Suparmoko (2002), memyatakan bahwa tenaga kerja yaitu orang yang berada dalam usia berkisaran 15-64 tahun.

b. Karakteristik berdasarkan masa kerja responden

Dari hasil penelitian pada Tabel 3 masa kerja pemanen terbanyak yaitu berkisaran 1-20 bulan dan masa kerja yang paling sedikit yaitu 61-80 bulan. Menurut Afifah dan Lubis (2016), bahwa lama kerja dapat mempengaruhi tingkat keterampilan dan pengalaman kerja karyawan.

c. Karakteristik berdasarkan pendidikan responden

Pada Tabel 4 dapat dilihat bahwa responden pada penelitian ini di dominasi oleh responden tamatan SD yaitu berjumlah 14 orang dari total jumlah responden.

Menurut Simamora dkk (2016), mengatakan bahwa sebagian besar tenaga kerja pemanen hanya mencapai tingkat pendidikan dasar (SD). Tenaga kerja di perusahaan sebagian besar memiliki pendidikan yang rendah. Hal tersebut terjadi karena perusahaan tidak memiliki standar pendidikan dalam penerimaan tenaga kerja di lapangan.

2. Tingkat pengetahuan tenaga kerja pemanen kelapa sawit

Berdasarkan pada Tabel 5 terdapat 5 pernyataan/indikator yang memiliki nilai katagori untuk setiap indikatornya, jumlah (frekuensi) terbanyak yaitu 55 dengan nilai katagori cukup baik dan nilai terendah yaitu 4 dengan nilai katagori baik dan sangat tidak baik. Hal ini diperoleh dari hasil pernyataan atau indikator pada pengetahuan pemanen.

Pada Tabel 6 dapat dilihat bahwa tingkat pengetahuan pemanen diketahui bahwa jumlah frekuensi 105 dengan presentasi $100 \%$ dan jumlah skor 380 dari seluruh tanggapan nilai katagori responden. Dalam perhitungan skor tertinggi 525 dan skor terendah 105 mendapatkan rentang skor yaitu 84 maka dapat digambarkan bahwa tanggapan responden masuk dalam katagori Baik dengan nilai 380.

Dari penelitian ini sejalan dengan Tanto dkk. (2012) yang menyatakan bahwa pengetahuan yang tinggi, keterampilan dan kepercayaan diri dapat meningkatkan prestasi kerja karyawan sehingga terwujud produktivitas kerja yang baik.

3. Produktivitas

Menurut Hartono (2005) salah satu cara mengukur efesiensi tenaga kerja dengan menghitung produktivitas kerja. Produktivitas kerja merupakan perbandingan antara tenaga kerja yang digunakan untuk menghasilkan produktivitas dalam satuan tertentu.

Dilihat dari produktivitas tenaga kerja pemanen memiliki rata-rata 222 janjang/HK. Tenaga kerja panen di PTSKJ menerapkan target atau basis 181 janjang/HK. Artinya tenaga kerja dapat melampaui basis yang telah ditargetkan oleh perusahaan. Dengan pengetahuan tenaga kerja pemanen termasuk katagori baik, produktivitas yang dicapai sudah melebihi basis yang ditentukan perusahaan.

\section{KESIMPULAN}

Berdasarkan hasil penelitian mengenai pengetahuan tenaga kerja pemanenan kelapa sawit dapat disimpulkan sebagai berikut:

1. Pengetahuan tenaga kerja pemanen kelapa sawit masuk dalam katagori Baik dengan nilai 380.

2. Rata-rata produktivitas tenaga kerja pemanenan di PT Sentosa Kalimantan Jaya yang dicapai 222 jajang/HK melampaui target yang telah ditentukan oleh perusahaan yaitu 181 janjang/HK.

\section{DAFTAR PUSTAKA}

Afifah, S.N dan Lubis, I. (2016). Faktor PEnentu Produktivitas Tenaga Kerja Panen Kelapa Sawit Kalimantan Timur. Jurnal Dapartemen Agronomi dan Hortikultura. Vol 4(2):215-223.

Arikunto, S. (2003). Prosedur Penelitian: suatu Pendekatan Praktik. Jakarta: Rineka Cipta.

Fauzi, Yan. (2012). Kelapa Sawit. Budidaya, Pemanfaat Hasil dan Limbah, Analisis Usaha dan Pemasaran. Jakarta: Penebar Swadaya.

Hartono, J.M. (2005). Analisis dan Desain Sistem Informasi: Pendekatan Terstruktur dan Praktek Aplikasi Bisnis. Yogyakarta: Andi Offset. 
Hasibun, M. (2009). Manajemen Sumber Daya Manusia. Jakarta: PT Bumi Aksara.

Iqbal, M. (2002). Pokok-pokok Materi Metode Penelitian dan Aplikasinya. Jakarta: Ghalia.

Lubis, A.U. (2008). Kelapa Sawit (Elaeis quineensis Jacq) di Indonesia Ed Ke-2. Jakarta: Pusat Penelitian Kelapa Sawit.

Mangoensoekarjo, S. Dan Semangun, H. (2008). Manajemen Agribisnis Kelapa Sawit. Gajah Mada University Press. 605 hal.

Simamora, A.W.F., Sayakti, W.D., dan Situmorang, S. (2016). Produktivitas Tenaga Kerja Pemanen di PT Perkebunan Nusantara VII Unit Kebun Kelapa Sawit Rejosari. Jurnal Agribisnis. Vol 4 No 2.

Singarimbun, M dan Effendi, S. (2011). Metode Penelitian Survei. Jakarta: LP3S.

Suparmoko, M. (2002). Ekonomi Publik Untuk Keuangan dan Pembangunan Daerah. Yogyakarta: Andi.

Sumarsono, S. (2009). Teori dan Kebijakan Publik Ekonomi Sumber Daya Manusia. Yogyakarta: Graha Ilmu.

Sugiyono, S. (2013). Metode Penelitian Bisnis. Bandung: CV. Alfabeta.

Tanto, D., Dewi, S.M., dan Budi, S.P. (2012). Faktorfaktor yang Mempengaruhi Produktivitas Pekerja pada Pengerjaan Atap Baja Ringan di Perumahan Green Hils Malang. J Rekayasa Sipil. 6(1):69-82 